\title{
Superabsorbent Polymer Based on Sodium Carboxymethyl Cellulose Grafted Polyacrylic Acid by Inverse Suspension Polymerization
}

\author{
Pairote Klinpituksa and Patchareeya Kosaiyakanon \\ Department of Science, Faculty of Science and Technology, Prince of Songkla University, Pattani 94000, Thailand \\ Correspondence should be addressed to Pairote Klinpituksa; kpairote31@gmail.com
}

Received 25 December 2016; Revised 1 February 2017; Accepted 12 February 2017; Published 27 March 2017

Academic Editor: Antje Potthast

Copyright ( 2017 Pairote Klinpituksa and Patchareeya Kosaiyakanon. This is an open access article distributed under the Creative Commons Attribution License, which permits unrestricted use, distribution, and reproduction in any medium, provided the original work is properly cited.

\begin{abstract}
A superabsorbent polymer (SAP) based on graft copolymerization of sodium carboxymethyl cellulose and acrylic acid was prepared by inverse suspension polymerization using potassium persulfate as an initiator and $\mathrm{N}, \mathrm{N}^{\prime}$-methylenebisacrylamide as a cross-linker. Experiments were performed at $70^{\circ} \mathrm{C}$ for $90 \mathrm{~min}$ but varying the concentrations of sodium carboxymethyl cellulose (NaCMC), acrylic acid (AA), potassium persulfate (KPS), and $\mathrm{N}, \mathrm{N}^{\prime}$-methylenebisacrylamide (MBA), and also varying \% neutralization of AA. The maximum swelling capacity for SAP was $544.95 \mathrm{~g} / \mathrm{g}$ in distilled water and $44.0 \mathrm{~g} / \mathrm{g}$ in $0.9 \% \mathrm{w} / \mathrm{v} \mathrm{NaCl}$ solution. This near optimal SAP was prepared using $2.0 \mathrm{~g} / 100 \mathrm{~mL} \mathrm{NaCMC}, 1.0 \mathrm{~mol} / \mathrm{L}$ AA with 70\% neutralization, $0.014 \mathrm{~mol} / \mathrm{L}$ KPS, and $0.01 \mathrm{~mol} / \mathrm{L}$ MBA.
\end{abstract}

\section{Introduction}

Superabsorbent polymers (SAPs) are cross-linked networks of a hydrophilic polymer, with a high capacity for water uptake [1]. SAPs are widely used in many products, such as disposable diapers, feminine napkins, soil for agriculture and horticulture, gel actuators, water-blocking taps, and drug delivery [2]. Natural-based superabsorbent polymers have gained much attention because of their biocompatibility, biodegradability, and nontoxicity [3]. The graft copolymerization of a vinyl monomer, such as acrylic acid, acrylamide, acrylonitrile, or hydroxyethyl methacrylate, onto natural polymers, particularly cellulose and its derivatives, is an important method for production of SAPs/hydrogels. Examples of such research include CMC- $g$-poly(AA-co-AM) [4], CMC-g-poly(NaAA) [5-7], CMC-g-poly(NaAA)/Kaolin [6], Poly CMC/poly(AA) [8], CMC-g-poly(AM-co-AMPS) [9], and CMC-g-poly(AA-co-AMPS) [10]. These studies have demonstrated that the introduction of hydrophilic monomers enhances or greatly improves the water absorbency and the swelling rate of SAP. However, most SAP products have been formed by aqueous solution polymerization. Inverse suspension polymerization is defined as the polymerization of a dispersed water-soluble monomer in a continuous organic matrix. The advantage of this approach over other methods is that a fine powdery product is obtained, and the particle size can be easily controlled by adjusting the reaction conditions. In recent years, the inverse suspension polymerization method has been successfully used to prepare water-soluble/swellable products, such as thickeners, flocculating agents, and superabsorbent hydrogels [11]. Only few studies have reported on preparation of SAPs by inverse suspension polymerization, such as CMC-g-poly(AM-coMAETAC) [12]. They have stated that the hydrophilelipophile balance (HLB) of stabilizer is of great importance to enhancing the swelling capacity of a cationic superabsorbent polymer.

The objective of this work was to prepare superabsorbent polymers by graft copolymerization of sodium carboxymethyl cellulose and acrylic acid/sodium acrylate in 
the presence of $\mathrm{N}, \mathrm{N}^{\prime}$-methylenebisacrylamide as a crosslinker and potassium persulfate as an initiator, by inverse suspension polymerization.

\section{Materials and Methods}

2.1. Materials. Sodium carboxymethyl cellulose (NaCMC), degree of substitution 0.60-0.95, was supplied by Fluka, Finland. Acrylic acid (AA, Analytical Reagent) was purchased from Merck, Germany. Potassium persulfate (KPS, Analytical Reagent) was purchased from APS Ajax Finechem, Australia. $\mathrm{N}, \mathrm{N}^{\prime}$-methylenebisacrylamide (MBA, Analytical Reagent) was purchased from Fluka, Switzerland. The other chemicals were of analytical grade and used as received without further purification.

\subsection{Preparation of NaCMC-g-AA Superabsorbent Polymer by Inverse Suspension Polymerization}

2.2.1. Preparation of Aqueous or Disperse Phase. Acrylic acid at $0.4-1.0 \mathrm{~mol} / \mathrm{L}$ in a $250 \mathrm{~mL}$ beaker was cooled in ice water. This acid was neutralized (65-80\% neutralization) by adding dropwise with stirring the desired amount of $10 \mathrm{M} \mathrm{NaOH}$ solution. Then 1.0-3.0 g/100 mL NaCMC and 0.006-0.014 mol/L $\mathrm{N}, \mathrm{N}^{\prime}$-methylenebisacrylamide (MBA) were added and stirred thoroughly. Additionally, $0.006-0.014 \mathrm{~mol} / \mathrm{L}$ potassium persulfate $\left(\mathrm{K}_{2} \mathrm{~S}_{2} \mathrm{O}_{8}\right.$, KPS) was added and mixed in, and the reaction mixture was adjusted to a total $75 \mathrm{~mL}$ volume by distilled water.

2.2.2. Preparation of Organic or Continuous Phase. $150 \mathrm{~mL}$ cyclohexane and $2.5 \mathrm{~g}$ Span 80 (stabilizer) were added to a $250 \mathrm{~mL}$ three-necked reactor, equipped with mechanical stirrer, dropping funnel and $\mathrm{N}_{2}$ inlet. The reactor was immersed in a thermostated water bath. The mixture was stirred at $40^{\circ} \mathrm{C}$ with $300 \mathrm{rpm}$ setting for $15 \mathrm{~min}$. The aqueous phase above was added slowly via dropping funnel while temperature was adjusted to $70^{\circ} \mathrm{C}$. The reaction was allowed to proceed for $90 \mathrm{~min}$. The reaction mixture was poured into excess ethanol and let stand for $12 \mathrm{~h}$ to dewater. The product obtained was filtered, washed 2-3 times with ethanol, and air dried at $50^{\circ} \mathrm{C}$ in an oven.

\subsection{Characterization}

2.3.1. FTIR Spectroscopy. FTIR spectra of the SAP samples were taken by Attenuated Total Reflectance-Fourier Transform Infrared (ATR-FTIR) Spectrophotometry using FTIR BRUKER/TENSOR 27, Switzerland.

2.3.2. Scanning Electron Microscopy (SEM). The surface morphology of pure NaCMC and NaCMC-g-PAA superabsorbent polymers was investigated by using Scanning Electron Microscope, JSM-5800LV, JEOL, Japan.

2.4. Water Absorbency Measurement. $0.1 \mathrm{~g}$ powdered superabsorbent polymer was immersed in $150 \mathrm{~mL}$ distilled water or $0.9 \% \mathrm{w} / \mathrm{v} \mathrm{NaCl}$ solution for $1.5 \mathrm{~h}$. The swollen polymer was filtered through a nylon screen and allowed to drain for $10 \mathrm{~min}$. The water absorbent capacity was calculated as follows:

$$
\text { Swelling }(\mathrm{g} / \mathrm{g})=\frac{W_{1}-W_{0}}{W_{0}} \times 100 \text {, }
$$

where $W_{0}$ and $W_{1}$ are the weights of dry gel and swollen gel, respectively.

\section{Results and Discussion}

3.1. Mechanism for Formation of NaCMC-g-PAA Superabsorbent Polymer. The formation of superabsorbent polymer (NaCMC-g-PAA) from NaCMC and acrylic acid/sodium acrylate in the presence of $\mathrm{N}, \mathrm{N}^{\prime}$-methylenebisacrylamide (MBA) was carried out using $\mathrm{K}_{2} \mathrm{~S}_{2} \mathrm{O}_{8}$ (KPS) as a free radical initiator. In the first step, KPS was thermally decomposed forming sulfate radical anions. These radicals then reacted possibly with water forming hydroxyl radicals. The hydroxyl radicals abstracted subsequently hydrogen atoms from NaCMC molecules to form reactive NaCMC macroradicals. Then the macroradicals initiated graft copolymerization of monomers (acrylic acid and sodium acrylate), and the MBA cross-linker led to the formation of crosslinked NaCMC-g-PAA. A possible reaction scheme for this superabsorbent polymer synthesis is given in Scheme 1.

\subsection{Characterization}

3.2.1. FTIR Analysis. Figure 1 shows the FTIR spectra of sodium carboxymethyl cellulose and cross-linked NaCMC$g$-PAA (superabsorbent polymer). The FTIR spectrum of the superabsorbent polymer shows new characteristic absorption bands at $1708 \mathrm{~cm}^{-1}$ attributed to $\mathrm{C}=\mathrm{O}$ stretching in the $-\mathrm{COOH}$ group of acrylic acid. The band at $1588 \mathrm{~cm}^{-1}$ is attributed to $\mathrm{C}=\mathrm{O}$ asymmetric stretching in carboxylate anion, and another sharp peak at $1409 \mathrm{~cm}^{-1}$ is related to the symmetric stretching mode of carboxylate anion $[4,13]$. Moreover, the band observed at $1163 \mathrm{~cm}^{-1}$ is attributed to $\mathrm{C}-\mathrm{N}$ stretching in MBA.

3.2.2. Scanning Electron Microscopy (SEM). Morphology of powdered $\mathrm{NaCMC}$ and $\mathrm{NaCMC}-\mathrm{g}-\mathrm{PAA}$ was investigated using a SEM. Figure 2(a) shows the SEM micrograph of $\mathrm{NaCMC}$. It is clear that the native $\mathrm{NaCMC}$ backbones formed rod-like crystal structures. In the case of the superabsorbent polymer (NaCMC-g-PAA), granular shaped structures were found due to the cross-linked polyacrylate incorporated onto NaCMC molecules, Figure 2(b).

\subsection{Optimization of Graft Copolymerization}

3.3.1. Effect of Partial Neutralization of Acrylic Acid. Figure 3 indicates that the swelling capacity of superabsorbent polymer increased with the degree of neutralization in the range from $65 \%$ to $70 \%$ degree of neutralization and then decreased considerably with further neutralization. As an explanation, increasing the degree of neutralization increases ionic carboxylate groups in the network, and this improves swelling 


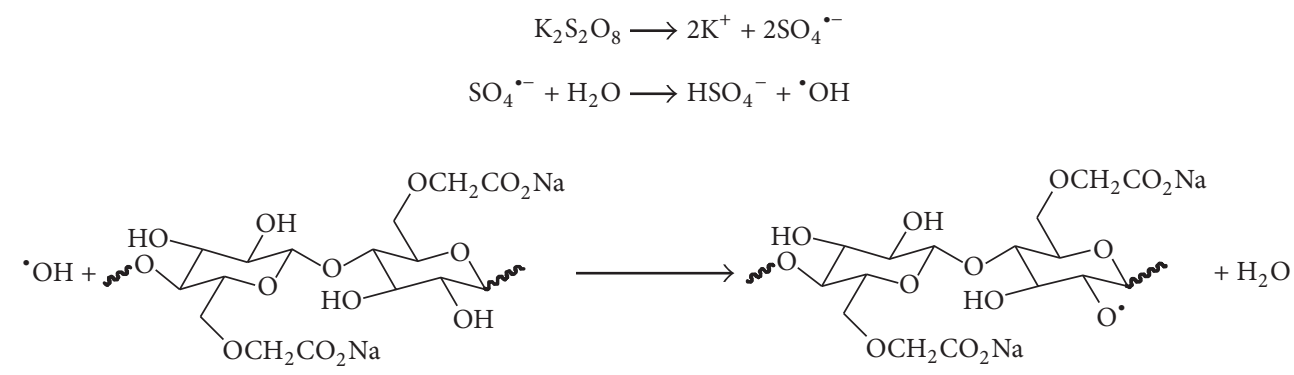

Sodium carboxymethyl cellulose (NaCMC)

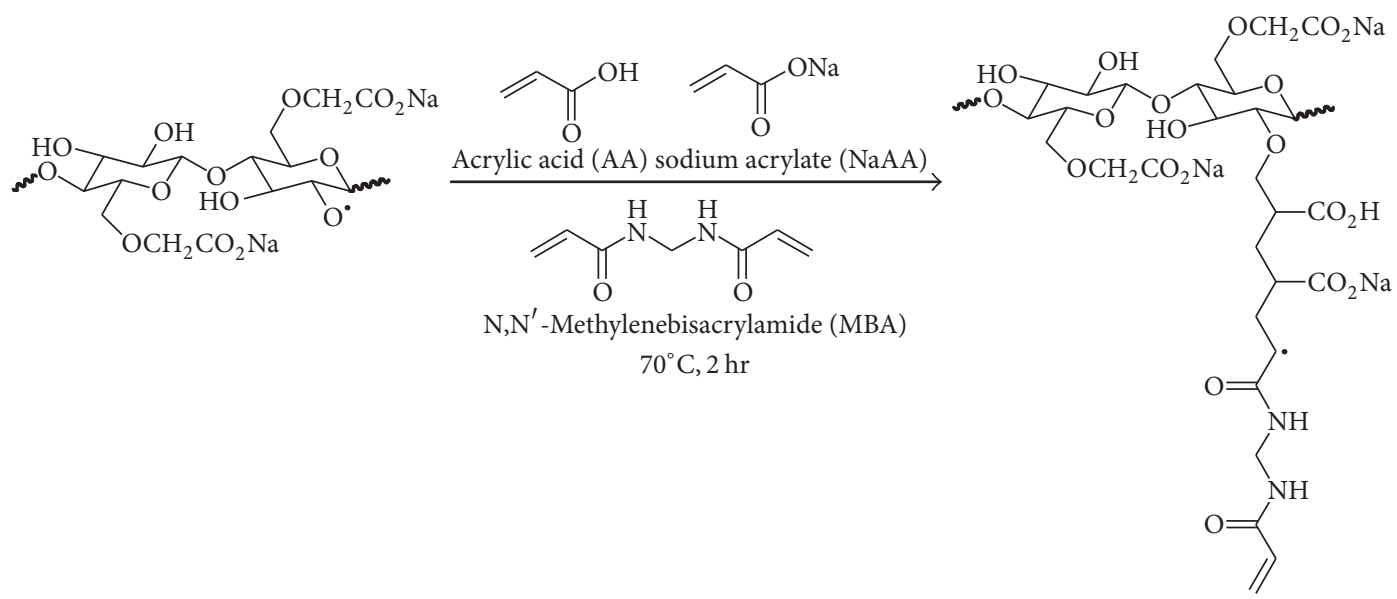

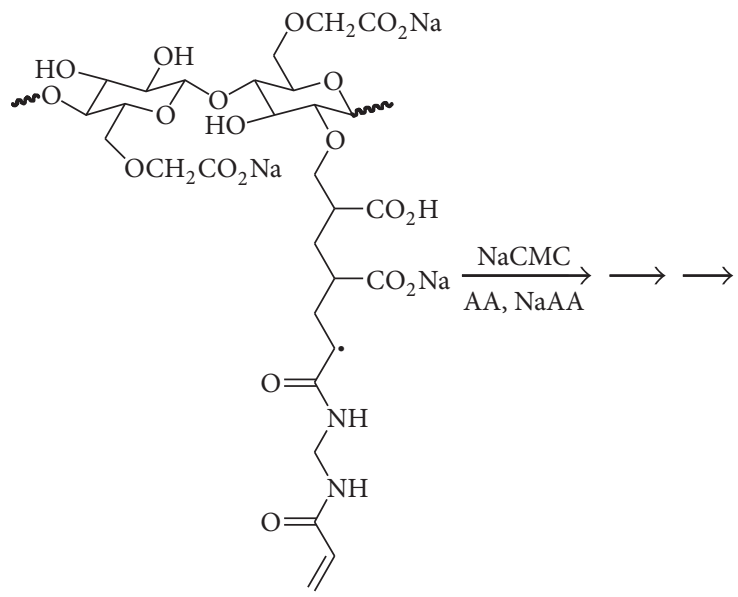

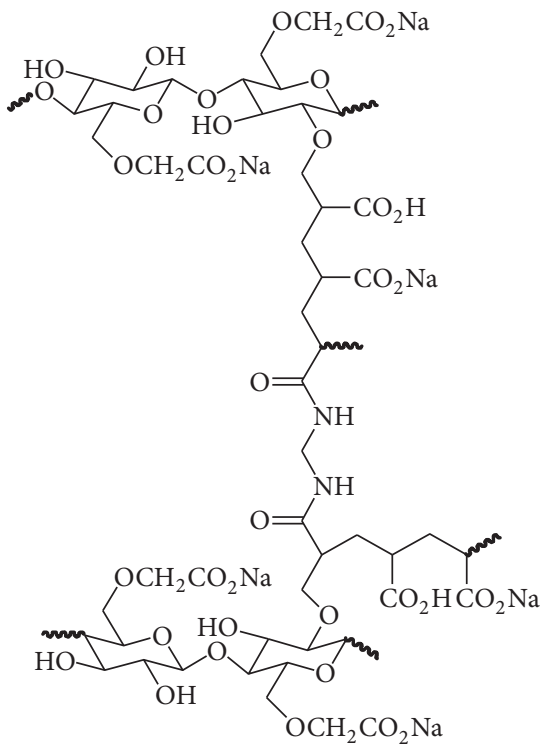

Cross-linked NaCMC-g-PAA

Scheme 1: A possible reaction scheme for the formation of SAP (cross-linked NaCMC-g-PAA).

because the ions are strongly solvated in an aqueous medium. In addition, the swelling capacity of superabsorbent polymer increased due to repulsion forces between adjacent carboxylate groups $\left(-\mathrm{COO}^{-}\right)$in the polymer network, facilitating volumetric expansion of the polymer with superabsorbent. However, at higher degrees of neutralization from 70 to $85 \%$, the swelling was reduced due to the $\mathrm{Na}^{+}$ions that act as a screen inside the network polymer, hindering the repulsion of $-\mathrm{COO}^{-}$groups and decreasing the swelling capacity.

\subsubsection{Effect of Potassium Persulfate (KPS) Concentration.} Figure 4 shows that the swelling capacity increased gradually with the KPS concentration from $0.006 \mathrm{~mol} / \mathrm{L}$ up to $0.014 \mathrm{~mol} / \mathrm{L}$, and then decreased considerably with further 


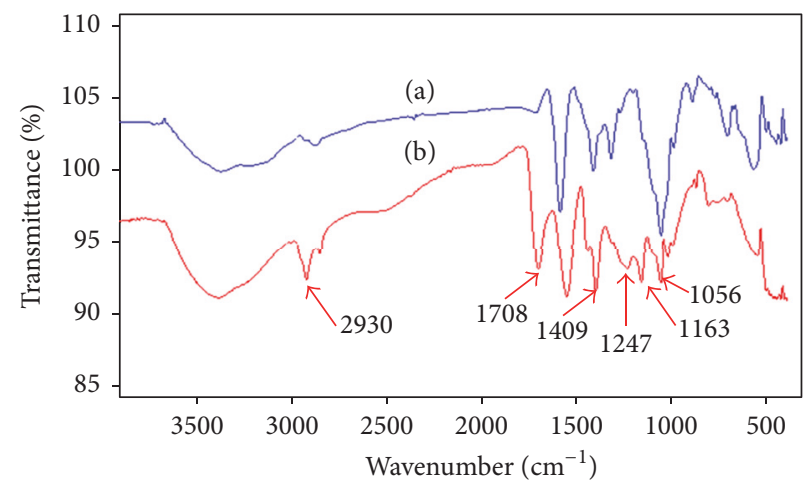

FIGURE 1: ATR-FTIR spectra of (a) NaCMC and (b) NaCMC-g-PAA superabsorbent polymer.

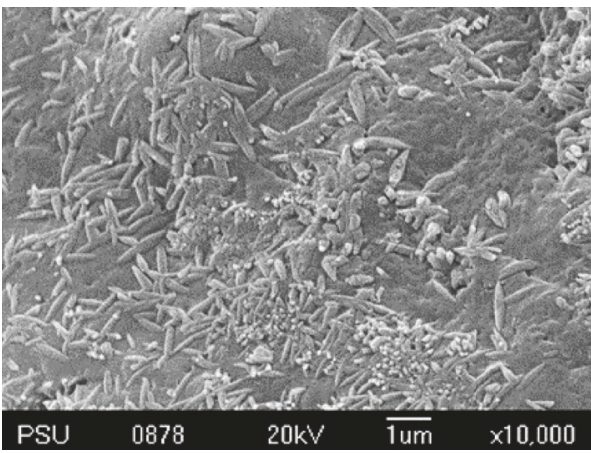

(a)

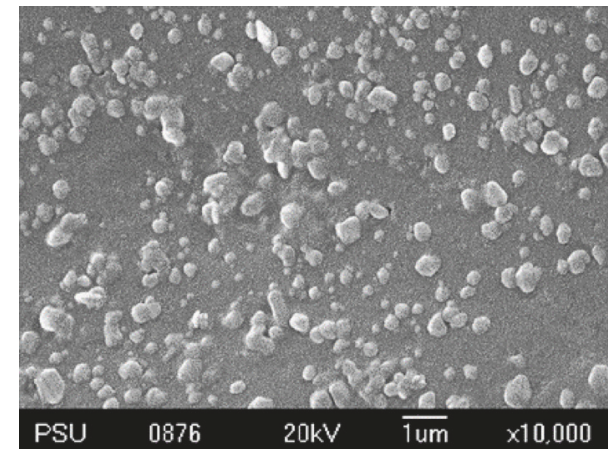

(b)

Figure 2: SEM micrographs of (a) NaCMC and (b) NaCMC-g-PAA superabsorbent polymer.

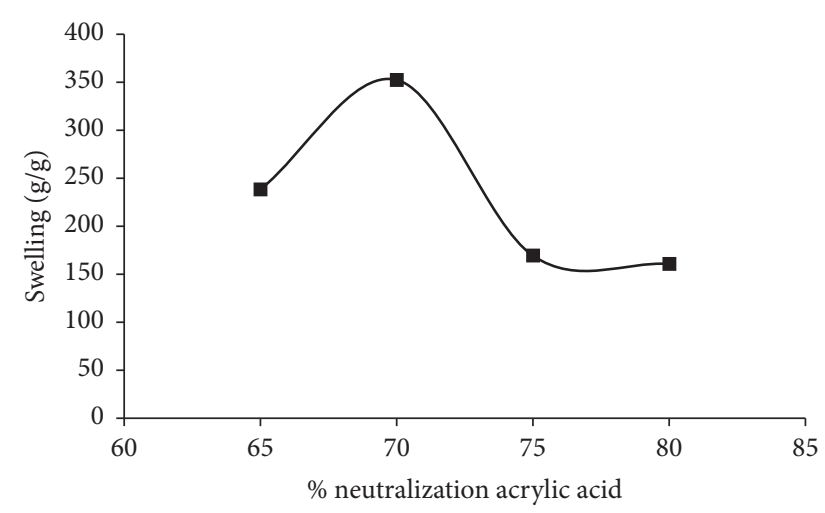

FIGURE 3: Effect of partially neutralized acrylic acid on swelling (reaction condition: $2.0 \mathrm{~g} / 100 \mathrm{~mL} \mathrm{NaCMC}, 0.8 \mathrm{~mol} / \mathrm{L} \mathrm{AA}, 0.01 \mathrm{~mol} / \mathrm{L}$ $\mathrm{KPS}$, and $0.01 \mathrm{~mol} / \mathrm{L} \mathrm{MBA} 70^{\circ} \mathrm{C}$ for $90 \mathrm{~min}$ ).

increase in KPS concentration. This is because the rate of polymerization increases with the number of free radicals produced in the initial production concentration. The later reduction in swelling capacity at high amounts of KPS may be due to termination steps with too abundantly produced radicals.

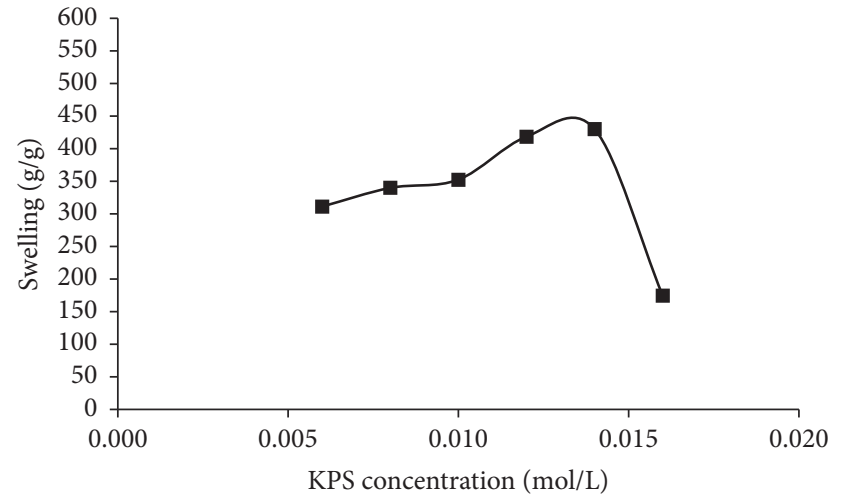

FIGURE 4: Effect of initiator (KPS) concentration on swelling capacity (reaction condition: $2.0 \mathrm{~g} / 100 \mathrm{~mL} \mathrm{NaCMC}, 0.8 \mathrm{~mol} / \mathrm{L} \mathrm{AA}$, $70 \%$ neutralized $\mathrm{AA}$, and $0.01 \mathrm{~mol} / \mathrm{L} \mathrm{MBA}$ at $70^{\circ} \mathrm{C}$ for $90 \mathrm{~min}$ ).

3.3.3. Effect of $N, N^{\prime}$-Methylenebisacrylamide (MBA) Concentration. Figure 5 shows the swelling capacity of crosslinked NaCMC-g-PAA as function of cross-linker (MBA) concentration. The swelling capacity increased with MBA concentration from $0.006 \mathrm{~mol} / \mathrm{L}$ and reached its maximum around $0.014 \mathrm{~mol} / \mathrm{L}$ of MBA. The SAP obtained possessed good dimensional stability for holding water inside network 


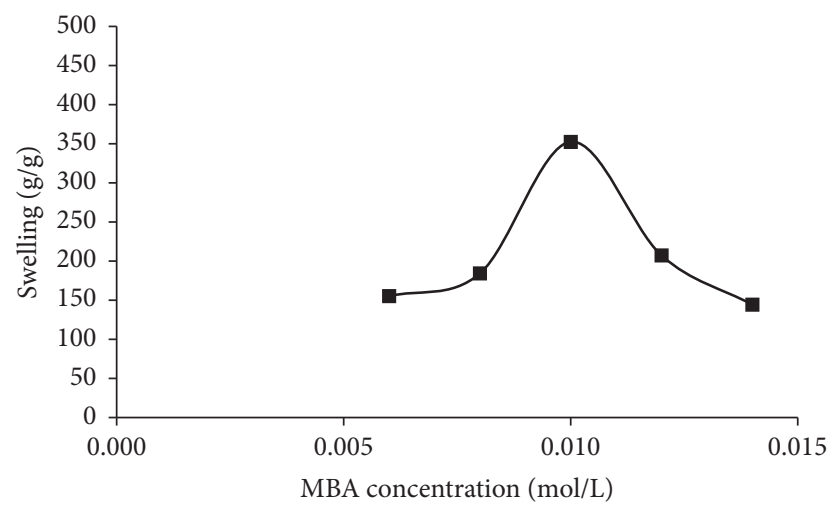

FIGURE 5: Effect of MBA on swelling capacity (reaction condition: $2.0 \mathrm{~g} / 100 \mathrm{~mL} \mathrm{NaCMC}, 0.8 \mathrm{~mol} / \mathrm{L} \mathrm{AA}, 70 \%$ neutralized AA, and $0.014 \mathrm{~mol} / \mathrm{L} \mathrm{KPS}$ at $70^{\circ} \mathrm{C}$ for $\left.90 \mathrm{~min}\right)$.

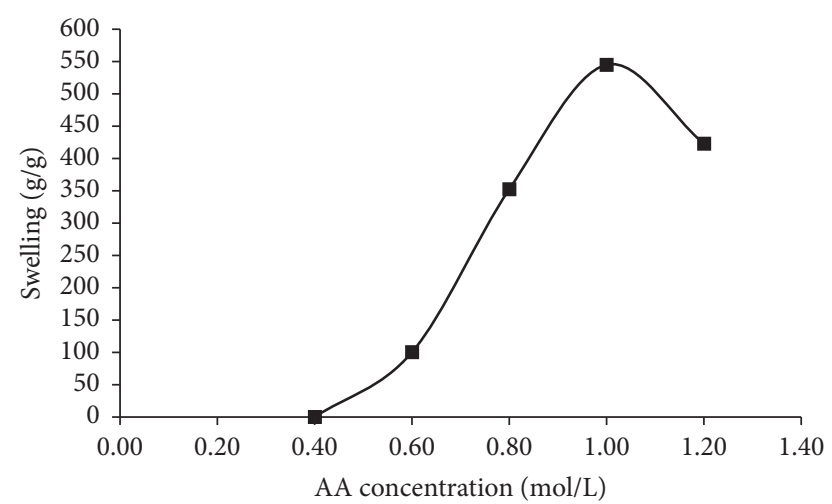

FIGURE 6: Effect of acrylic acid concentration on swelling capacity (reaction condition: $2.0 \mathrm{~g} / 100 \mathrm{~mL} \mathrm{NaCMC}, 0.01 \mathrm{~mol} / \mathrm{L} \mathrm{MBA}, 70 \%$ neutralized $\mathrm{AA}$, and $0.014 \mathrm{~mol} / \mathrm{L} \mathrm{KPS}$ at $70^{\circ} \mathrm{C}$ for $90 \mathrm{~min}$ ).

with the proper amount of MBA. However, the swelling capacity decreased with further increases in the MBA concentration, as the strongly cross-linked rigid structure could not expand and swell in water [14].

3.3.4. Effect of Acrylic Acid (AA) Concentration. The dependence of swelling capacity of NaCMC- $g$-PAA on acrylic acid concentration is illustrated in Figure 6. The swelling capacity increased with AA concentration from $0.4 \mathrm{~mol} / \mathrm{L}$ up to $1.0 \mathrm{~mol} / \mathrm{L}$ and then decreased with further increases in AA concentration. The initial increase in swelling capacity may originate from the greater availability of monomer molecules in the vicinity of the chain propagating sites of NaCMC macromolecules. Furthermore, a higher acrylic acid/acrylate salt content enhances the hydrophilicity in the superabsorbent causing stronger solvation with water. However, the final decrease in absorbency may be due to (a) preferential homopolymerization over graft copolymerization or (b) an increase in the viscosity of the medium that hindered the movement of free radicals or (c) an increased chance of chain transfer to monomer molecules [15].

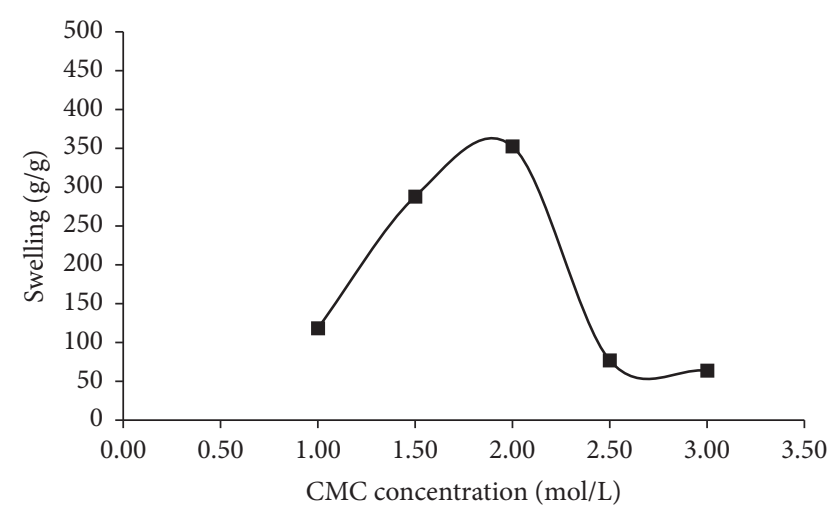

FIGURE 7: Effect of sodium carboxymethyl cellulose (NaCMC) on swelling capacity (reaction condition: $1.0 \mathrm{~mol} / \mathrm{L} \mathrm{AA}, 70 \%$ neutralized AA, $0.01 \mathrm{~mol} / \mathrm{L} \mathrm{MBA}$, and $0.014 \mathrm{~mol} / \mathrm{L} \mathrm{KPS}$ at $70^{\circ} \mathrm{C}$ for $90 \mathrm{~min}$ ).

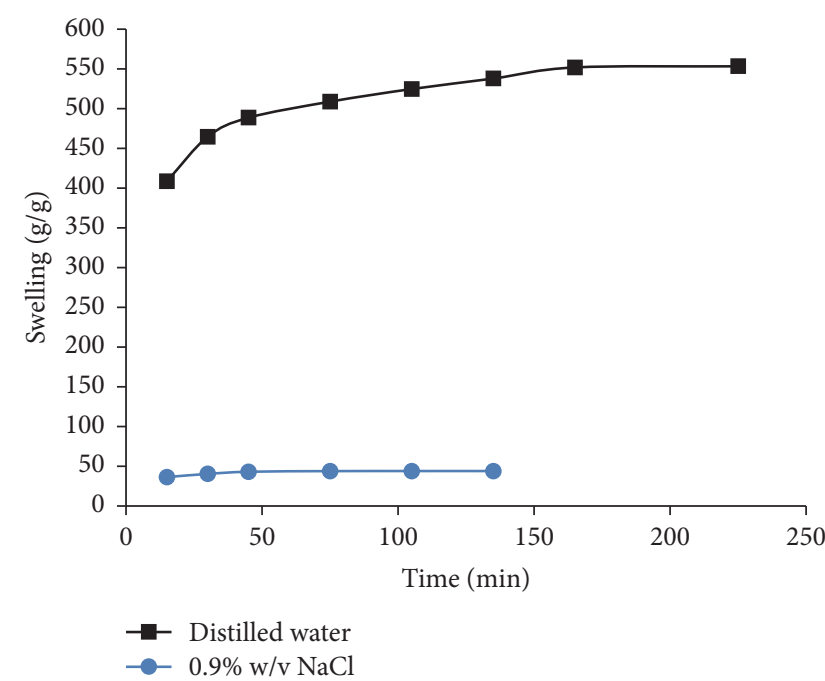

FIGURE 8: Effect of time on swelling capacity in distilled water and $0.9 \% \mathrm{w} / \mathrm{v} \mathrm{NaCl}$ solution (reaction condition: $2.0 \mathrm{~g} / 100 \mathrm{~mL}$ $\mathrm{NaCMC}, 1.0 \mathrm{~mol} / \mathrm{L} \mathrm{AA}, 70 \%$ neutralized AA, $0.01 \mathrm{~mol} / \mathrm{L} \mathrm{MBA}$, and $0.014 \mathrm{~mol} / \mathrm{L} \mathrm{KPS}$ at $70^{\circ} \mathrm{C}$ for $90 \mathrm{~min}$ ).

3.3.5. Effect of Carboxymethyl Cellulose Concentration. Figure 7 presents the effect of sodium carboxymethyl cellulose on swelling capacity of NaCMC-g-PAA. Initially with the $\mathrm{NaCMC}$ concentration from 1.0 to $2.0 \mathrm{~g} / 100 \mathrm{~mL}$ the swelling capacity increased and then decreased after a maximum. The initial increase may be due to the increased availability of grafting sites leading to better swelling capacity, where $\mathrm{NaCMC}$ can be grafted. The subsequent decrease in grafting at high $\mathrm{NaCMC}$ concentrations resulted in lower swelling capacity, due to increased viscosity of medium that hindered the movement of free radicals.

3.3.6. Effect of Salt Content on Water Absorbency. The swelling capacity of optimized SAP in $0.9 \% \mathrm{w} / \mathrm{v} \mathrm{NaCl}$ solution in distilled water is shown in Figure 8, along with swelling in distilled water without salt. The maximum adsorption was found to be $544.95 \mathrm{~g} / \mathrm{g}$ without salt and $44.0 \mathrm{~g} / \mathrm{g}$ in the $0.9 \%$ $\mathrm{w} / \mathrm{v} \mathrm{NaCl}$ solution. The reduction of swelling capacity of this 
TABLE 1: The maximum swelling capacity in distilled water for some superabsorbent polymers/hydrogels based on CMC and free radical solution polymerization, with present results in the last row for comparison.

\begin{tabular}{lcc}
\hline Superabsorbent polymer/hydrogel based on CMC & Maximum swelling capacity (g/g) & Reference \\
\hline Poly CMC-g-poly(AA-co-AM) & 920 & Suo et al. [4] \\
Poly CMC-g-poly(NaAA) & $317-634$ & Wang et al. [6] \\
Poly CMC-g-poly(NaAA) & 322 & Hosseinzadeh and Sadeghi, 2012 [7] \\
Poly CMC-g-poly(NaAA)/Kaolin & 392 & Hosseinzadeh and Sadeghi, 2012 [7] \\
Poly CMC/poly(AA) blend & 165 & Sutradhar et al. [8] \\
Poly NaCMC-g-poly(AA) & 544.95 & Present work \\
\hline
\end{tabular}

SAP by $\mathrm{NaCl}$ in solution is attributed to the decrease of osmotic pressure between the gel network and the external solution, caused by the screening effect of $\mathrm{Na}^{+}$ions [9]. It is well known that the ideal performance of superabsorbers is generally vastly degraded when tested, for example, with urine, affecting applications in diapers.

The maximum swelling capacity of poly CMC-gpoly(AA) prepared by free radical inverse suspension polymerization in the present work is listed in Table 1, along with literature curated capacities of superabsorbent polymers/hydrogels obtained by free radical solution polymerization.

\section{Conclusions}

The superabsorbent polymer, NaCMC-g-PAA, was successfully prepared through grafting of acrylic acid onto sodium carboxymethyl cellulose in the presence of KPS as an initiator and MBA as a cross-linker by inverse suspension polymerization. The optimized preparation conditions of this polymer were $2.0 \mathrm{~g} / 100 \mathrm{~mL} \mathrm{NaCMC}, 1.0 \mathrm{~mol} / \mathrm{L}$ AA with $70 \%$ neutralization, $0.014 \mathrm{~mol} / \mathrm{L} \mathrm{KPS}$, and $0.01 \mathrm{~mol} / \mathrm{L} \mathrm{MBA}$. The maximum swelling capacity of this superabsorbent polymer was $544.95 \mathrm{~g} / \mathrm{g}$ in distilled water and $44.0 \mathrm{~g} / \mathrm{g}$ in $0.9 \% \mathrm{w} / \mathrm{v}$ $\mathrm{NaCl}$ solution.

\section{Conflicts of Interest}

The authors declare that there are no conflicts of interest regarding the publication of this paper.

\section{Acknowledgments}

The authors thank Faculty of Science and Technology, Prince of Songkla University, Thailand, for facility support.

\section{References}

[1] H. F. Mark, Encyclopedia of Polymer Science and Technology, vol. 8, John Wiley \& Sons, Hoboken, NJ, USA, 3rd edition, 2003.

[2] M. Sadeghi, B. Heidari, and K. Montazeri, "Investigation of evaluation of swelling kinetics related to biopolymers based on CMC-poly(AA-co-BuMC)," International Scholarly and Scienctific Research \& Innovation, vol. 51, pp. 217-219, 2011.

[3] M. Sadeghi and H. Hosseinzadeh, "Swelling behavior of a novel protein-based superabsorbent hydrogel composed of poly(methylacrylic acid) and collagen," Asian Journal of Chemistry, vol. 22, no. 9, pp. 6734-6746, 2010.
[4] A. Suo, J. Qian, Y. Yao, and W. Zhang, "Synthesis and properties of carboxymethyl cellulose-graft-poly(acrylic acid-coacrylamide) as a novel cellulose-based šuperabsorbent," Journal of Applied Polymer Science, vol. 103, no. 3, pp. 1382-1388, 2007.

[5] Y. Chen, Y.-F. Liu, and H.-M. Tan, "Preparation of macroporous cellulose-based superabsorbent polymer through the precipitation method," BioResources, vol. 3, no. 1, pp. 247-254, 2008.

[6] W. B. Wang, J. X. Xu, and A. Q. Wang, "A pH-, salt- and solventresponsive carboxymethylcellulose-g-poly(sodium acrylate)/ medical stone superabsorbent composite with enhanced swelling and responsive properties," eXPRESS Polymer Letters, vol. 5, no. 5, pp. 385-400, 2011.

[7] H. Hosseinzadeh and M. Sadeghi, "Preparation and swelling behaviour of carboxymethylcellulose-g-poly(sodium acrylate)/ kaolin super absorbent hydrogel composites," Asian Journal of Chemistry, vol. 24, no. 1, pp. 85-88, 2012.

[8] S. C. Sutradhar, M. M. R. Khan, M. M. Rahman, and N. C. Dafadar, "The synthesis of superabsorbent polymers from a carboxymethylcellulose/acrylic acid blend using gamma radiation and its application in agriculture," Journal of Physical Science, vol. 26, no. 2, pp. 23-39, 2015.

[9] A. Pourjavadi, H. Ghasemzadeh, and F. Mojahedi, "Swelling properties of CMC-g-poly(AAm-co-AMPS) superabsorbent hydrogel," Journal of Applied Polymer Science, vol. 113, no. 6, pp. 3442-3449, 2009.

[10] Y. Z. Wang, X. N. Shi, W. B. Wang, and A. Q. Wang, "Synthesis, characterization, and swelling behaviors of a $\mathrm{pH}$-responsive CMC-g-poly(AA-co-AMPS) superabsorbent hydrogel," Turkish Journal of Chemistry, vol. 37, no. 1, pp. 149-159, 2013.

[11] H. Omidian, M. J. Zohuriaan-Mehr, and H. Bouhendi, "Polymerization of sodium acrylate in inverse-suspension stabilized by sorbitan fatty esters," European Polymer Journal, vol. 39, no. 5, pp. 1013-1018, 2003.

[12] D. Wang, S.-B. Shang, Z.-Q. Song, and Y. Wang, "Synthesis and property of superabsorbent polymers modified by carboxymethyl cellulose," Chemistry and Industry of Forest Products, vol. 27, no. 5, pp. 6-10, 2007.

[13] A. Pourjavadi, G. R. Mahdavinia, and M. J. Zohuriaan-Mehr, "Modified chitosan. II. H-chitoPAN, a novel pH-responsive superabsorbent hydrogel," Journal of Applied Polymer Science, vol. 90, no. 11, pp. 3115-3121, 2003.

[14] M. Sadeghi and M. Yarahmadi, "Synthesis and characterization of superabsorbent hydrogel on chitisan-g-poly(acrylic acid-coacrylonitrile," African Journal of Biotechnology, vol. 10, no. 57, pp. 12265-12275, 2011.

[15] A. Pourjavadi and G. R. Mahdavinia, "Superabsorbency, $\mathrm{pH}$-sensitivity and swelling kinetics of partially hydrolyzed chitosan-g-poly(acrylamide) hydrogels," Turkish Journal of Chemistry, vol. 30, no. 5, pp. 595-608, 2006. 

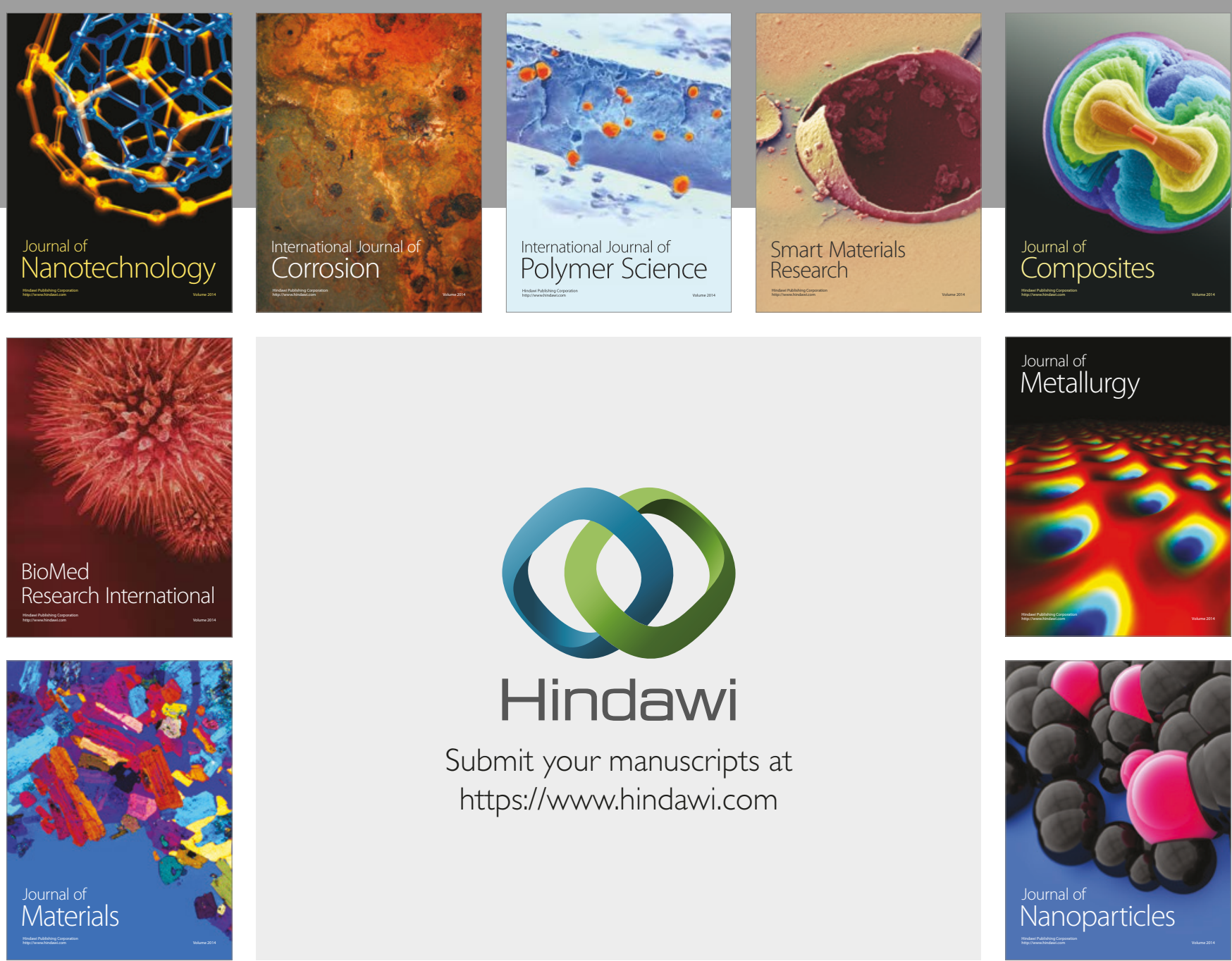

\section{Hindawi}

Submit your manuscripts at

https://www.hindawi.com
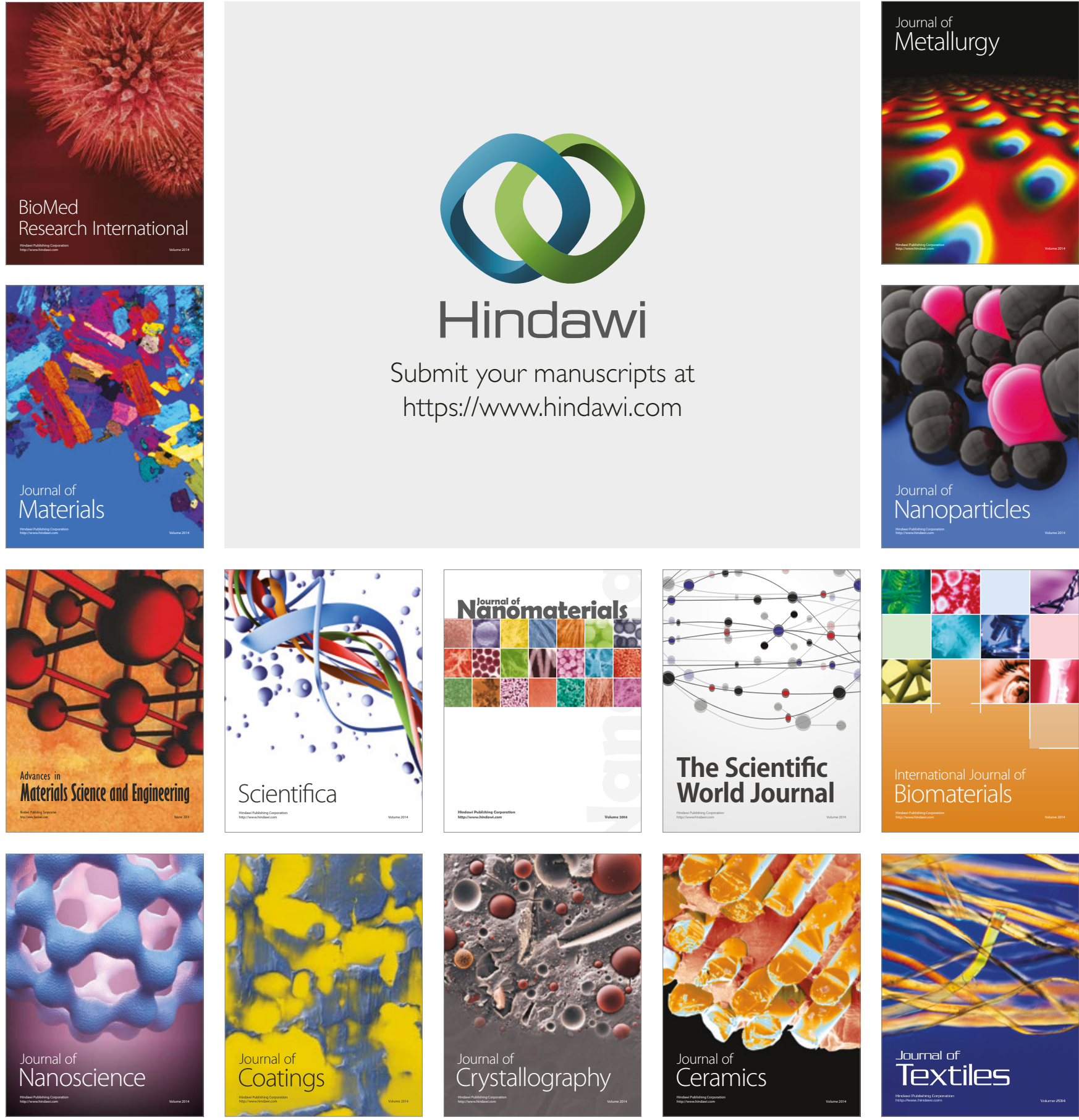

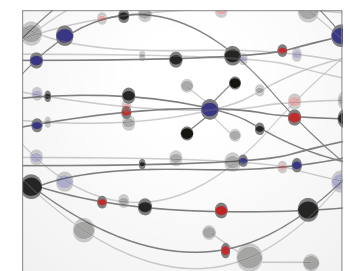

The Scientific World Journal
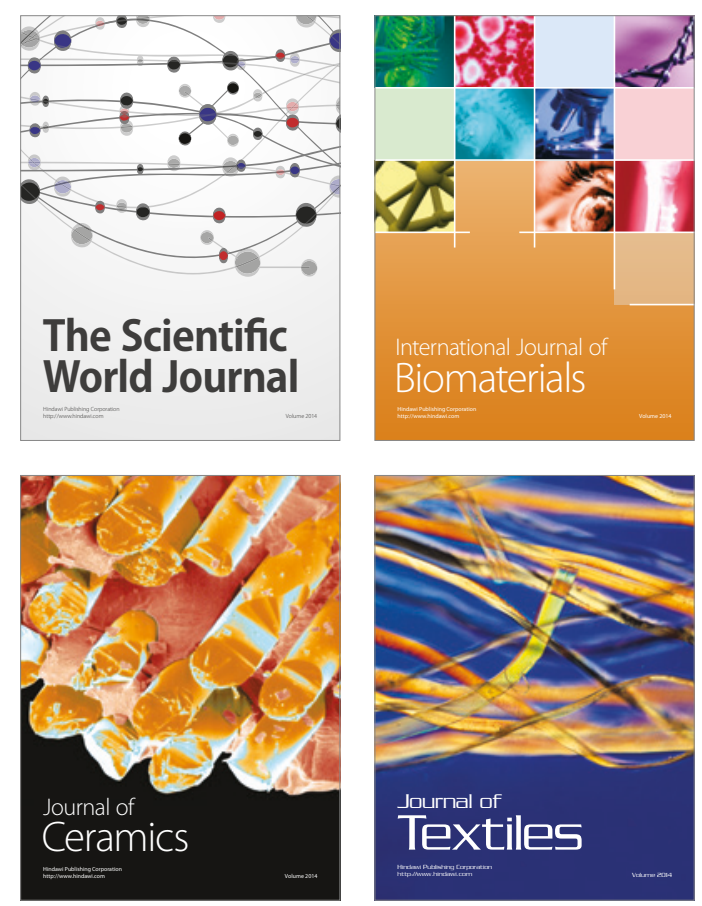